\title{
Reversible Myocardial Dysfunction after Subarachnoid Bleed
}

Sir,

Neurogenic stunned myocardium (NSM) is defined as myocardial injury and dysfunction occurring after various types of acute brain injury due to central autonomic disorders. After taking consent from next of kin we present a case of NSM following subarachnoid bleed managed at our hospital.
A 60-year-old female without any history of significant comorbidities presented to one healthcare facility with a history of sudden loss of consciousness and respiratory distress. On examination, she was hypotensive having diffuse ST-T changes on electrocardiogram (ECG) with transthoracic echocardiography revealing global hypokinesia, 


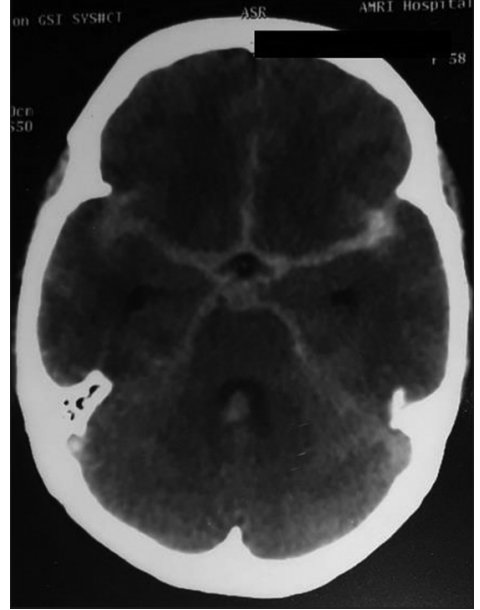

Figure 1: Computed tomography scan showing subarachnoid bleed

gross systolic dysfunction (ejection fraction - 31\%), and Grade II diastolic dysfunction. Quantitative troponin level was $1736 \mathrm{ng} / \mathrm{L}$. After stabilization with ventilator support and inotropes, she underwent plain computed tomography (CT) scan which revealed massive acute subarachnoid bleed [Figure 1]. Her condition continued to improve over the next day when she underwent CT angiography revealing right-sided middle cerebral artery aneurysm [Figure 2]. She continued to improve dramatically and was referred to our center for further management. On arrival at our hospital, she was hemodynamically stable, conscious, and well oriented. Although ST-T changes were persisting on ECG, repeat echo demonstrated marked improvement in cardiac function and repeat value of troponin came as $0.43 \mathrm{ng} / \mathrm{L}$. She underwent 4-vessel cerebral angiography and coiling of aneurysm under general endotracheal anesthesia uneventfully. Her cardiac status continued to improve over the next few days and was discharged in a hemodynamically and neurologically stable condition. As NSM has commonly been described in patients with subarachnoid hemorrhage, ${ }^{[1-4]}$ the majority of NSM data comes from studies concerning this group of patients. Features key to the identification of NSM are fully reversible postischemic dysfunction and that the dysfunction is not caused by a primary defect in myocardial perfusion. Our patient had reversible cardiac dysfunction which is indicative of neurogenic cause mimicking true myocardial injury although coronary angiogram needed to be done to strengthen our diagnosis. The pathomechanism of NSM has not been fully elucidated. It was once assumed that the condition resulted from ischemia of the myocardium caused by the contraction of epicardial coronary vessels and microcirculation disorders. Currently, it is believed that the most likely cause of NSM changes is catecholamine-induced myocardial damage. ${ }^{[1,2,5]}$ As NSM syndrome has been described only recently, there are no clear guidelines for its management. It is generally believed that treatment directed at the acute cerebral injury underlying NSM is essential. ${ }^{[3]}$ Further studies are required to broaden our knowledge about the pathomechanisms

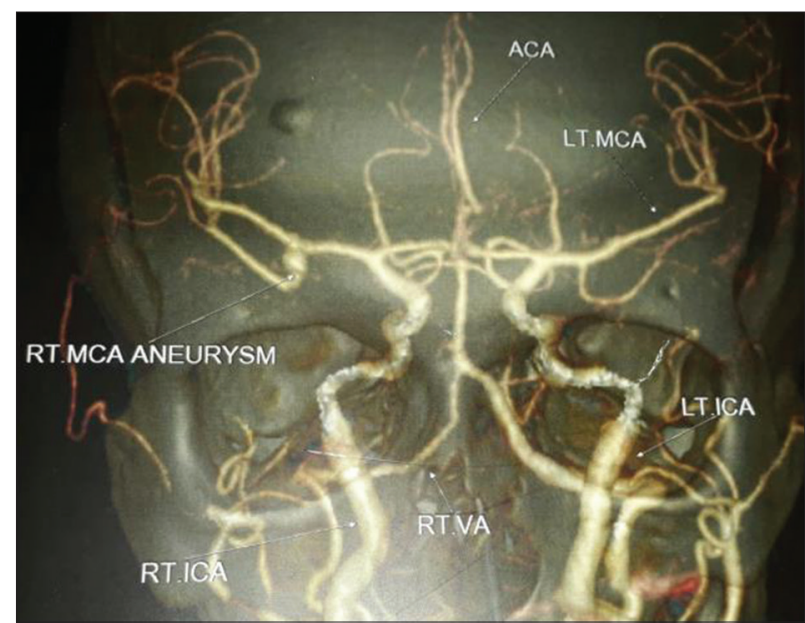

Figure 2: Computed tomography angiogram showing aneurysm

underlying NSM syndrome and to find the most effective methods of its treatment and prevention. It seems essential to determine the effects of exogenous catecholamines on NSM. Once their negative influence is confirmed, alternative methods of treatment should be sought. As left ventricular dysfunction is frequently associated with subarachnoid bleed, there are a lot of clinical and pathophysiological similarities with transient left ventricular apical ballooning syndrome or takotsubo cardiomyopathy. ${ }^{[6]}$ Each type of reversible left ventricular dysfunction mediated by the central nervous system and initiated by acute brain injury, both physical, such as intracranial bleeding or head traumas, and psychological, such as sudden emotional stress, could be encompassed in a single definition with larger inclusion criteria, such as "acute ballooning cardiomyopathy" that is likely to be more representative of the real needs in the clinical setting. ${ }^{[6]}$

\section{Declaration of patient consent}

The authors certify that they have obtained all appropriate patient consent forms. In the form the patient(s) has/have given his/her/their consent for his/her/their images and other clinical information to be reported in the journal. The patients understand that their names and initials will not be published and due efforts will be made to conceal their identity, but anonymity cannot be guaranteed.

\section{Financial support and sponsorship}

Nil.

\section{Conflicts of interest}

There are no conflicts of interest.

Indranil Ghosh, Sukalyan Purakayastha1, Bibhukalyani Das Departments of Neuroanaesthesiology and ${ }^{1}$ Neuroradiology, Institute of Neurosciences, Kolkata, West Bengal, India

Address for correspondence: Dr. Indranil Ghosh, "Sudha" Flat No. 4, $3^{\text {rd }}$ Floor 75/65 S N Roy Road, Kolkata, West Bengal, India. E-mail: ghoshindranilghosh@rediffmail.com 


\section{References}

1. Bybee KA, Prasad A. Stress-related cardiomyopathy syndromes. Circulation 2008;118:397-409.

2. Nguyen H, Zaroff JG. Neurogenic stunned myocardium. Curr Neurol Neurosci Rep 2009;9:486-91.

3. Devos J, Peeters A, Wittebole X, Hantson P. High-dose insulin therapy for neurogenic-stunned myocardium after stroke. BMJ Case Rep 2012;2012. pii: bcr2012006620

4. Divekar A, Shah S, Joshi C. Neurogenic stunned myocardium and transient severe tricuspid regurgitation in a child following nonaccidental head trauma. Pediatr Cardiol 2006;27:376-7.

5. Parekh N, Venkatesh B, Cross D, Leditschke A, Atherton J, Miles $\mathrm{W}$, et al. Cardiac troponin I predicts myocardial dysfunction in aneurysmal subarachnoid hemorrhage. J Am Coll Cardiol 2000;36:1328-35

6. Trio $\mathrm{O}$, de Gregorio C, Andò G. Myocardial dysfunction after subarachnoid haemorrhage and tako-tsubo cardiomyopathy: A differential diagnosis? Ther Adv Cardiovasc Dis 2010;4:105-7.
This is an open access article distributed under the terms of the Creative Commons Attribution-NonCommercial-ShareAlike 3.0 License, which allows others to remix, tweak, and build upon the work non-commercially, as long as the author is credited and the new creations are licensed under the identical terms.

\begin{tabular}{|l|l|}
\hline \multicolumn{3}{|c|}{ Access this article online } \\
\hline Quick Response Code: & Website: \\
& www.ijccm.org \\
& \\
&
\end{tabular}

How to cite this article: Ghosh I, Purakayastha S, Das B. Reversible myocardial dysfunction after subarachnoid bleed. Indian J Crit Care Med 2017;21:877-9.

C 2017 Indian Journal of Critical Care Medicine | Published by Wolters Kluwer - Medknow 